$\begin{array}{ll}\begin{array}{l}\text { Florin-Eugen } \\ \text { Constantinescu } \\ \text { DMD, PhD Student } \\ \text { Holistic Dental \& Medical Institute } \\ \text { of Bucharest- ROPOSTURO, } \\ \text { Bucharest, Romania } \\ \text { e-mail: } \\ \text { dr.florin.constantinescu@gmail.com }\end{array} & \begin{array}{l}\text { Imaging of the } \\ \text { Temporomandibular Joint }\end{array} \\ & \begin{array}{l}\text { Editors: Ingrid Rozylo-Kalinowska, Kaan Orhan } \\ \text { Publisher: Springer International Publishing }\end{array} \\ \text { AG, Germany } \\ \text { Language: English } \\ \text { ISBN: } 978-3-319-99467-3 \\ \text { Edition: } 1 / \text { e } \\ \text { Publish Year: } 2019 \\ \text { Pages: } 406, \text { illustrated } \\ \text { Price: } 160,49 €\end{array}$

\section{Imaging of the Temporomandibular Joint}

Editors: Ingrid Rozylo-Kalinowska, Kaan Orhan AG, Germany

Language: English

Edition: 1/e

Pages: 406, illustrated

Price: $160,49 €$

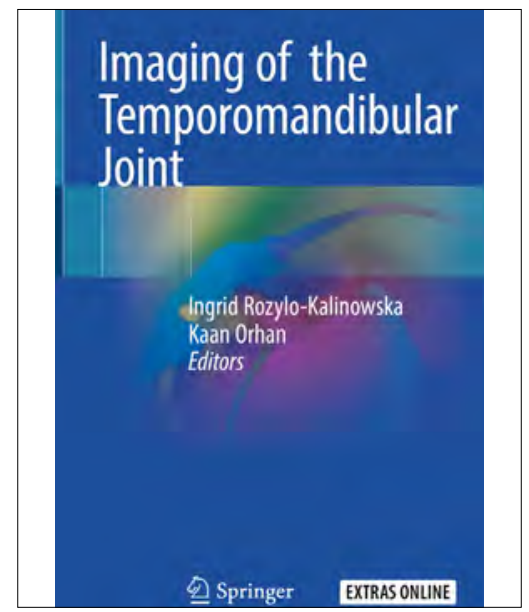

The discovery of X-ray, 120 years ago by Conrad Roentgen, to which CBCT, MRI, and ultrasonography have been added much later, has made radiological imaging an undisputed support in the diagnosis of maxillofacial disease. This book has been designed to provide as much information as possible from temporomandibular joint (TMJ) imaging in order to establish a correct diagnosis of TMJ disorders. The book is divided in twenty chapters.

After the introductory chapters on anatomy, histology and the bases of radiological imaging, there follows detailed guidance on the use and interpretation of radiography, CT, CBCT, ultrasound, MRI and nuclear medicine techniques. Further on, the authors discuss and illustrate a wide range of TMJ pathologies, osteoarthritis, inflammatory diseases, traumatic conditions, and a number of benign tumors.

In a separate chapter, the authors focus on the use of arthrography and arthrography-guided steroid treatment. And then there is a conjunction between TMJ and temporal bone, and benign and malignant tumors of the ear and temporal bone. Finally, micro-CT applications are presented in TMJ research and genetic studies on TMJ pathologies.

The higly-illustrated book titled "Imaging of the Temporomandibular Joint", written by an international team of dedicated authors, is a comprehensive review of dentomaxillofacial imaging, useful for dentists who deal with TMJ pathology, as well as specialized neuro- or head and neck radiologists.

DOI: https://doi.org/10.25241/stomaeduj.2019.6(1).bookreview.7

The Books Review is drafted in the reviewer's sole wording and illustrates his opinions.

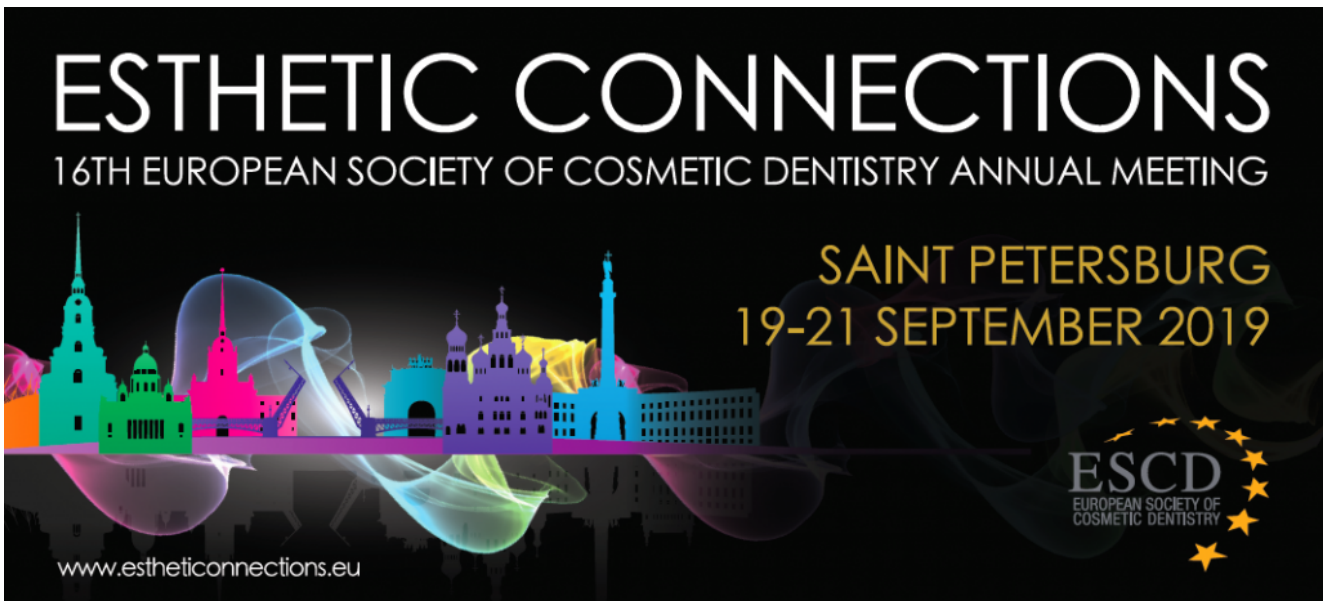

https://escdonline.eu/19-21-sep-2019-st-petersburg-16th-escd-annual-meeting-esthetic-connections/ 